\title{
Correction to: Hymenobacter oligotrophus sp. nov., isolated from a contaminated agar plate
}

\author{
Yingchao Geng $\cdot$ Yumin Zhang $\cdot$ Jin Tian · Jia Liu $\cdot$ Kun Qin • \\ Yao Huang $\cdot$ Ziyan Wei $\cdot$ Fang Peng $(\mathbb{D}$
}

Published online: 28 January 2020

(C) Springer Nature Switzerland AG 2020

\section{Correction to:}

Antonie van Leeuwenhoek (2019) 112:1533-1544

https://doi.org/10.1007/s10482-019-01279-3

In the original publication, the deposit number of strain sh- $6^{\mathrm{T}}$ was incorrectly published as "CCTCC AB
2016064" throughout the article. However, the correct deposit number is "CCTCC AB 2016306".

Publisher's Note Springer Nature remains neutral with regard to jurisdictional claims in published maps and institutional affiliations.

The original article can be found online at https:// doi.org/10.1007/s10482-019-01279-3.

Y. Geng $\cdot$ Y. Zhang $\cdot$ J. Tian · J. Liu $\cdot$ K. Qin .

Y. Huang $\cdot$ Z. Wei $\cdot$ F. Peng $(\square)$

China Center for Type Culture Collection (CCTCC),

College of Life Sciences, Wuhan University,

Wuhan 430072, China

e-mail: fangpeng2@aliyun.com 